Clinical Studies 


\title{
Marking Disappearing Colorectal Liver Metastases After Complete Response to Neoadjuvant Chemotherapy via CT - A Pilot Study
}

\author{
JOVAN VUJIC ${ }^{1}$, HELMUT SCHÖLLNAST ${ }^{2}$, KATHARINA MARSONER ${ }^{1}$, VALERIE WIENERROITHER ${ }^{1}$, \\ HEINZ BACHER $^{1}$, HANS-JÖRG MISCHINGER ${ }^{1}$ and PETER KORNPRAT ${ }^{1}$ \\ ${ }^{1}$ Division of General Surgery, Department of Surgery, Medical University of Graz, Graz, Austria; \\ ${ }^{2}$ Department of Radiology, Medical University of Graz, Graz, Austria
}

\begin{abstract}
Background/Aim: The liver is a frequent site for metastases of colorectal cancer. Approximately $15 \%$ of patients have hepatic metastases at the time of diagnosis and another $50 \%$ develop them over the course of their disease. Only 10$25 \%$ of patients are candidates for liver resection. The aim of this study was to assess the benefit of preoperative computed tomography (CT)-guided wire marking of disappearing colorectal liver metastases (CRLMs) (radiological disappearance of metastases) before surgical resection. Patients and Methods: Between January 2011 and January 2014, 20 patients with potentially disappearing CRLMs were selected for CT-guided wire marking. Following treatment with neoadjuvant chemotherapy, disappearing CRLMs were marked via CT guidance. Afterwards, the marked sites were resected. Results: Complete histological response to neoadjuvant chemotherapy was only in 10 resected sites (18\%), and 46 (82\%) resected liver metastases showed metastatic tissue present. Both overall survival and the disease-free rates in patients after using our method were 55\%. Conclusion: This study demonstrated the usefulness of CT-guided wire marking to mark disappearing CRLMs in order to improve long-term effectiveness of surgical treatment.
\end{abstract}

Colorectal cancer is the third most frequent form of cancer in men and the second most frequent in women in Western countries, while the liver is most common site of metastasis

This article is freely accessible online.

Correspondence to: Peter Kornprat, MD, Division of General Surgery, Department of Surgery, Medical University of Graz, Auenbruggerplatz 29, 8036 Graz, Austria. Tel: +43 31638580524, e-mail: peter.kornprat@medunigraz.at

Key Words: Disappearing liver metastases, wire marking, colon cancer, complete radiological response. of colorectal cancer (1). About $20 \%$ of these patients suffer from hepatic metastases at the time of diagnosis and another $50 \%$ subsequently develop metastases to the liver $(2,3)$. The majority of these patients receive systemic treatment due to unresectable disease (4). Response to neoadjuvant chemotherapy often shows a down-sizing of colorectal liver metastases (CRLMs), which leads to resectability.

Preoperative chemotherapy in patients at high risk of recurrence may identify responders so that therapy can be tailored postoperatively. Furthermore, it is a good selection tool in patients with multiple tumors, as those whose disease progresses under chemotherapy may not benefit from resection (5). The pathological response to preoperative chemotherapy is strongly predictive of prognosis after resection. However, the value of complete radiological response is unclear $(6,7)$ and some studies question its concordance with full pathological response (8). Despite disappearance on cross-sectional imaging, complete pathological response occurs in $50 \%$ of total number of disappearing CRLMs (8). The main problem that motivated our research was operability and lack of precise options for resection of disappearing CRLMs of colorectal cancer.

Furthermore, authors such as Bischof et al. (9) and Elias et al. (10) have highlighted our own main concern that leaving disappearing CRLMs in situ following systemic preoperative chemotherapy is associated with increased risk of intrahepatic recurrence and mortality, so there is a necessity for a more efficient method for marking of tissue for precise histopathological analysis. Our technique of fiducial marking of CRLMs may improve survival rates by ensuring a pathological response to a treatment procedure and overcome the insecurity of mere radiological response. The modern-day therapeutic approach to the liver metastases of colorectal cancer is through various chemotherapy regimens. Metastases that were once diagnostically confirmed disappear to a certain extent in computed tomography (CT) or magnetic resonance imaging (MRI). Such metastases were left untreated $(10,11)$. With a 
recurrence rate of up to $83 \%$ of untreated disappearing CRLMs (11), clinical effectiveness is a necessity.

Our use of wire marking of CRLMs by CT guidance in a test case is one possible means by which to overcome the problem of disappearing CRLMs and to our knowledge the first in the literature. This innovative perspective, but also widespread model of marking in breast cancer proved to be a cost-effective solution (12). Our goal was to mark metastatic tissue of colonic carcinoma in the liver with a wire as used in breast marking so that after chemotherapy, when such CRLMs may no longer be detectable by CT (i.e. disappearing CRLMs), they might be resected in such a precise manner that unaffected liver tissue does not sustain any unnecessary loss, thereby leading to improved survival rates. Furthermore, by applying this kind of treatment procedure ('treat to resection'), the inclusion of patients considered for resection can be dramatically improved $(13,14)$.

The aim of this study was to evaluate our experience with fiducial marker placement for CRLMs likely to disappear with chemotherapy, including indications, safety, and outcomes. The best management of these patients is still under debate. However, it has been demonstrated that liver resection should include all original sites of disease if possible.

\section{Patients and Methods}

Patient selection. We selected 20 patients with CRLMs between January 2011 and January 2014. Patients with the following criteria were included: i) Histologically proven colorectal carcinoma with synchronous (within 12 months) CRLM(s); ii) preoperatively administered neoadjuvant chemotherapy with fully radiological response of CRLMs (CT- or MRI-proven) or decrease in size of CRLMs to $\leq 1 \mathrm{~cm}$; iii) feasible surgical-technical resectability of the CRLMs.

The Institutional Review Board approved this prospective study and waived the need for patient consent according to the Declaration of Helsinki and its own criteria (EK 23-441-ex10/11).

The only criteria for patient drop-out was patient request.

Preoperative oncological treatment. Different preoperative systemic therapy regimes were applied for metastatic disease. The majority of the patients $(8 / 20,40 \%)$ received folinic acid/fluorouracil/oxaliplatin (FOLFOX)/bevacizumab). Two patients (10\%) received monotherapy with capeticabine. Other regimes included combinations with FOLFOX, folinic acid/fluorouracil/irinotecan (FOLFIRI) and incorporation of targeted biological therapies (bevacizumab, panitumumab and cetuximab). The average duration for the chemotherapy, which was applied in 6 cycles, was 6 months.

Imaging algorithm. Staging of disease in all patients was initially performed via contrast-enhanced CT (thorax, abdomen and pelvis). After receiving neoadjuvant chemotherapy, re-staging was performed either through contrast-enhanced CT or MRI. The entire process of imaging was carried out at the Department of Radiology, Medical University of Graz. The imaging scans were reviewed and evaluated by experienced radiologists in the field of oncology and hepato-biliary surgeons. Measurement and assessment of the response rate was performed using Response Evaluation Criteria in Solid Tumors (RECIST) 1.0 criteria (14). Postoperative recurrence was performed via CT every 3-6 months for a median average of 21 months.

CT-guided wire marking technique. Based on our experience in a case from 2009 (7), the technique was follows: Using the CT scan performed before neoadjuvant chemotherapy, CRLMs which might be expected to disappear were located and a wire with a hook at the top (X-Reidy Breast Lesion Localization Needle; Cook Medical, Cook Österreich GmbH, Vienna, Austria) was placed percutaneously at the site. On the day of surgery, with the patient under general anesthesia and antibiotic prophylaxis, CRLMs were marked using CT guidance and were immediately admitted after confirming wire placement.

Surgical approach. After wire placement, all patients were transferred under general anesthesia. All patients underwent open surgery via right subcostal incision. The initial surgical approach included a thorough examination for extrahepatic metastases as well as an obligatory ultrasound of the liver (PRO FOCUS Ultrasound; BK Medical Systems, Quickborn, Germany) and palpation of the complete liver for missed metastases. The wire location was identified and sufficient liver tissue around the tip of the wire was removed. All resected specimens were intraoperatively sent for frozen section analysis. Our first reason for this was to demonstrate the presence of tumor cells, and the second to qualify R0 resection margins. Depending on the tumor location, various resection techniques were applied. The majority $(\mathrm{n}=12,60 \%)$ were atypical segment resections. The median procedural duration (measured as skin-to-skin time) was 139 minutes. Average blood loss was $375 \mathrm{ml}$ and therefore hemostyptics (fibrin glue and fibrinogen/thrombin sponge; TachoSil ${ }^{\circledR}$; Takeda Pharmaceuticals Austria GmbH, Vienna, Austria) were placed in all procedures for hemorrhage control. At least one subhepatic drainage was positioned for postoperative control. Representative images of resected and marked tissue of the liver are depicted in Figure 1.

Follow-up protocol. Post procedural and post hospital follow-up of all 20 treated patients was carried out over a median period of 21.45 months. Kaplan-Meier plot was used to depict the overall and disease-free survival function of our patients for total follow-up period of 60 months.

Statistical analysis. Data were acquired prospectively and saved on an institutional liver database including baseline data, pre-, intraand postoperative parameters, results of histopathologic assays and follow-up details. Data were collected prospectively in an Excel database (Microsoft Österreich, Vienna, Austria). All statistical analyses were performed with SPSS 22.0 for Windows (IBM Inc., Somers, USA; IBM Österreich, Vienna-Graz, Austria). If not indicated otherwise, continuous variables were reported as means and standard deviation; categorical data were reported as counts and percentages. Categorical variables were compared with Fisher's exact or chi-square test, as appropriate; for numeric variables, Wilcoxon test was used. A value of $p<0.05$ was considered according to the method of Kaplan and Meier. Differences between subgroups were compared with log-rank test. 
A

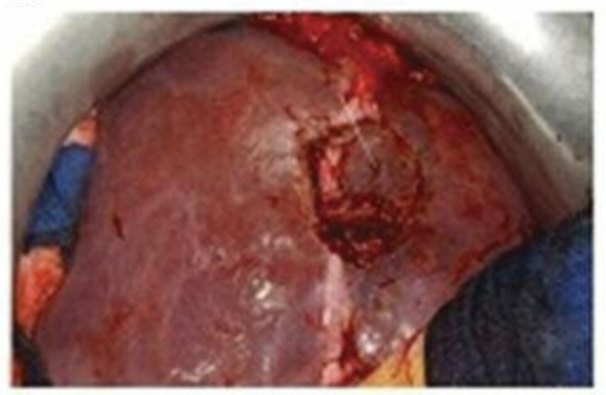

C

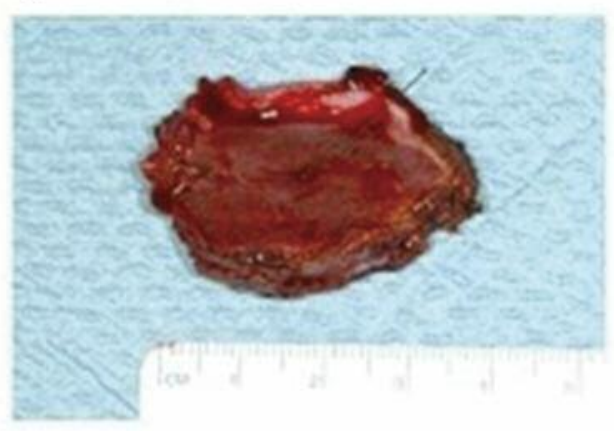

B

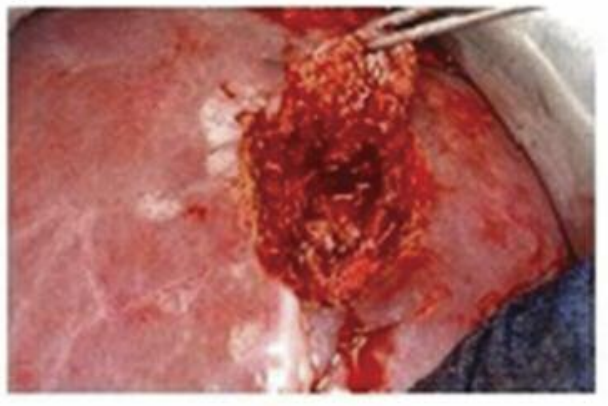

D

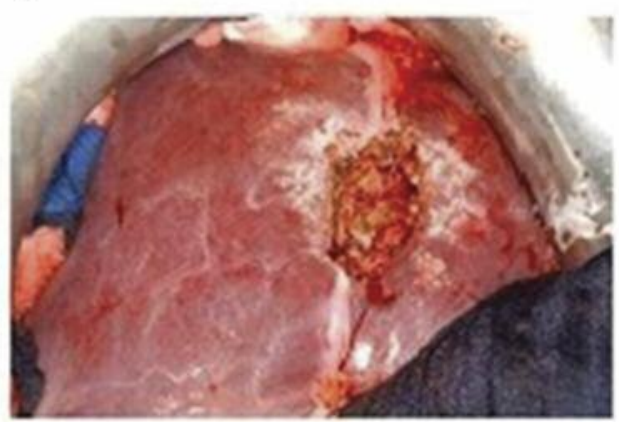

Figure 1. Wire marking of liver metastases. View of wire-marked metastatic tissue intraoperatively (A), and during removal (B). C: Resected metastatic tissue. D: Liver after completion of resection.

\section{Results}

Patient characteristics. The characteristics of the patient group are shown in Table I. A total of 19 patients received chemotherapy and 19 had a radiological response to chemotherapy, whilst one patient had neither therapy nor response (Table II). None of our patients had extrahepatic metastases. Regarding surgical characteristics, the majority, that is $12(60 \%)$ of our patients underwent atypical segment resection because of the localization of disappearing CRLMs (Table III), and 18 of our patients underwent complicationfree wire positioning. The median duration of wire-marking was 30 minutes (Table IV). A median of three metastases were wire-marked per patient.

Histopathological analysis. Histopathological analysis of 56 liver metastases showed that complete histological response to preoperative chemotherapy was achieved in only 10 resections (18\%), whilst $24(43 \%)$ resected liver metastases showed necrotic metastatic tissue and in $22(39 \%)$ samples, viable metastatic tissue was found. Histopathological analysis of primary tumors in patient cases is shown in Table II. Local complete radiological response was noted in six out of 56 metastases.
Disease-free survival. Postprocedural and posthospital follow-up of all 20 treated patients was carried out for a median period of 21.45 months. At the last follow-up, the number of patients without evidence of disease was 11 $(55 \%)$, whilst the number of patients who were classified as alive with disease was seven (35\%). Two of our patients $(10 \%)$ had a mortal outcome, with preoperative disease as a proven cause of death. Follow-up data are displayed in Table V. A non-parametric statistical method of Kaplan-Meier plot was used to depict the overall (Figure 2) and disease-free (Figure 3) survival function of our patients in the overall follow-up period (60 months). It is notable that approximately $12(60 \%)$ of our patients had the best outcome in the follow-up period from 1.5 years to 3.5 years. The rapid decline afterwards was due to loss of patients to follow-up.

\section{Discussion}

The main issue that motivated our research were disappearing CRLMs caused by therapy of colorectal cancer metastases. In studies conducted in 2006 and after, it is noted that around $10-25 \%$ of patients are considered for surgical resection, and if not resected, patients receive chemotherapy that is often used with palliative intent (15). Imaging, 
Table I. Demographic and preoperative patient data $(n=20)$.

\begin{tabular}{lc}
\hline Baseline data & Value \\
\hline Median age (IQR), years & $65.5(58.25-72.00)$ \\
Female gender, $\mathrm{n}(\%)$ & $6(30 \%)$ \\
Median BMI (IQR), $\mathrm{kg} / \mathrm{m}^{2}$ & $25.53(23.29-27.55)$ \\
ASA classification, $\mathrm{n}(\%)$ & \\
I & $1(5 \%)$ \\
II & $3(15 \%)$ \\
III & $16(80 \%)$ \\
IV & 0 \\
Location of carcinoma, n (\%) & \\
Cecum & $2(10 \%)$ \\
Right hemicolon & $3(15 \%)$ \\
Colon transversum/left colonic flexure & $3(15 \%)$ \\
Left hemicolon & $1(5 \%)$ \\
Sigmoid colon & $2(10 \%)$ \\
Rectosigmoid & $1(5 \%)$ \\
Rectum & $8(40 \%)$ \\
Primary tumor in situ & $6(30 \%)$ \\
\hline
\end{tabular}

BMI: Body mass index; ASA: American Society of Anesthesiologists.

particularly CT scans, are used to monitor the response, and those sites of liver tissue that are determined to be free of metastases after chemotherapy are considered to have disappeared. During surgery, only ultrasound scans can be used to detect residual sites of metastasis for resection, if they are shown by CT. A further study in 2012 clearly provided insights into the problem of disappearing CRLMs by showing $25-45 \%$ of patients had metastatic tissue in sites that were considered tumor-free based on CT scans (9).

Conversion to resection therapy is associated with prolonged survival (13). Focusing on this, we aimed to reduce the possible risks of tissue loss, treating with intention of resection, and with that improved the overall outcome (13) (Table II). For most of our patients, we used FOLFOX/bevacizumab combination (40\%) and FOLFOX alone $(20 \%)$ as preoperative chemotherapy. A study from 2016 had pinpointed that systemic chemotherapy typically converts previously unresectable CRLMs to resection with curative intent in only approximately $15-20 \%$ of patients (16). Our goal was resection of metastatic tissue locations smaller than $1 \mathrm{~cm}$ and those that were deemed likely to disappear after chemotherapy in CT and MRI. Our preoperational procedure precisely aimed at markings using a technique that is simple, cost-efficient and available (CTguided wire marking) and allows surgeons to find spots for metastatic resection with maximal precision. The literature shows that those sites of metastasis smaller than $1 \mathrm{~cm}$ and those disappearing from CT scans after chemotherapy are usually left unresected due to the impossibility of the surgeon being able to find them during surgery $(11,12)$. The
Table II. Histopathological and oncological details of primary tumor. Histopathological data available for cases with prior resection of colorectal carcinoma $(n=14)$.

\begin{tabular}{|c|c|}
\hline Feature & Value \\
\hline \multicolumn{2}{|l|}{ Histopathological details, n (\%) } \\
\hline $\mathrm{G} 2$ & $10(71 \%)$ \\
\hline G3 & $4(29 \%)$ \\
\hline T1 & 0 \\
\hline $\mathrm{T} 2$ & $1(7 \%)$ \\
\hline $\mathrm{T} 3$ & $10(71 \%)$ \\
\hline $\mathrm{T} 4$ & $3(21 \%)$ \\
\hline No & $5(36 \%)$ \\
\hline $\mathrm{N} 1$ & $7(50 \%)$ \\
\hline N2 & $2(14 \%)$ \\
\hline L0 & $5(36 \%)$ \\
\hline L1 & $9(64 \%)$ \\
\hline V0 & $7(50 \%)$ \\
\hline $\mathrm{V} 1$ & $7(50 \%)$ \\
\hline Median lymph node ratio (IQR) & $0.10(0.00-0.18)$ \\
\hline Synchronous hepatic metastases, n (\%) & $14(70 \%)$ \\
\hline Metachronous hepatic metastases, $\mathrm{n}(\%)$ & $6(30 \%)$ \\
\hline \multicolumn{2}{|l|}{ Oncological treatment, $\mathrm{n}(\%)$} \\
\hline Capeticabine & $2(10 \%)$ \\
\hline FOLFOX & $4(20 \%)$ \\
\hline FOLFIRI & $1(5 \%)$ \\
\hline FOLFOX/bevacizumab & $8(40 \%)$ \\
\hline FOLFOX/FOLFIRI/bevacizumab & $1(5 \%)$ \\
\hline FOLFIRI//bevacizumab & $1(5 \%)$ \\
\hline FOLFOX/panitumumab & $1(5 \%)$ \\
\hline FOLFIRI/cetuximab & $1(5 \%)$ \\
\hline None & $1(5 \%)$ \\
\hline Median duration (IQR), months & $6(3.00-6.00)$ \\
\hline \multicolumn{2}{|l|}{$\begin{array}{l}\text { Radiological response to oncological } \\
\text { treatment, } \mathrm{n}(\%)\end{array}$} \\
\hline Response & $18(90 \%)$ \\
\hline Stable disease & $1(5 \%)$ \\
\hline Not applicable & $1(5 \%)$ \\
\hline Median no. of hepatic metastases (IQR) & $3(1.25-4.00)$ \\
\hline Median diameter of metastasis (IQR), cm & $0.70(0.50-1.38)$ \\
\hline Median no. of metastases $<1 \mathrm{~cm}$ (IQR) & $1.50(1.00-2.00)$ \\
\hline Median serum CEA (IQR), $\mu \mathrm{g} / 1$ & $2.90(1.53-9.48)$ \\
\hline
\end{tabular}

CEA: Carcinoembryonic antigen; FOLFOX: folinic acid/5fluoruracil/oxaliplatin; FOLFIRI: folinic acid/5-fluoruracil/irinotecan; IQR: interquartile range. No patient had extrahepatic metastases. *TNM classification.

median number of wire-marked metastases in our study was three per patient, and for those smaller than $1 \mathrm{~cm}$ was 1.50 .

Furthermore, when the practical aspect is considered, it was noted in the work of Vigano et al. that early recurrence was reduced in patients who underwent anatomic resection and increased among patients who had intraoperative radiofrequency ablation associated with resection (15). Our surgical resection was conducted in such a manner that all unnecessary tissue loss was avoided, and only marked sites were resected (Tables III and IV). 
Table III. Intra- and postoperative patient data $(n=20)$.

\begin{tabular}{lc}
\hline Surgical details & Value \\
\hline Type of resection, n (\%) & \\
Left hemihepatectomy & $1(5 \%)$ \\
Right hemihepatectomy & $1(5 \%)$ \\
Central liver resection & $1(5 \%)$ \\
Atypical segmental resection & $12(60 \%)$ \\
Left hemihepatectomy with atypical & \\
segmental resection & $4(20 \%)$ \\
Atypical segmental resection and stoma reversal & $1(5 \%)$ \\
Median skin-to-skin time (IQR), min & $139(96-172)$ \\
Pringle maneuver, n (\%) & $1(5 \%)$ \\
Resection with laser scalpel, n (\%) & $20(100 \%)$ \\
Hemostyptics, n (\%) & $17(85 \%)$ \\
Fibrin glue & $3(15 \%)$ \\
Fibrinogen/thrombin sponge (TachoSil $\left.{ }^{\circledR}\right)$ & $375(200-775)$ \\
Median intraoperative blood loss (IQR), ml & $2.00(1.00-2.00)$ \\
Median no. of intra-abdominal drainages (IQR) & \\
Postoperative complications & \\
according to CDC, n (\%) & $18(90 \%)$ \\
CDC 0 & $2(10 \%)^{*}$ \\
CDC IIIa & $10(8-12)$ \\
Median in-hospital stay (IQR), days &
\end{tabular}

CDC: Clavien-Dindo classification (28). *Pneumothorax, liver abscess.

Table IV. Details of wire marking procedure.

\begin{tabular}{lc}
\hline Details of wire marking intervention & Value \\
\hline Median no. of (IQR) & $3(1.25-4.00)$ \\
Median no. of WMM <1 cm (IQR), & $1.50(1.00-2.75)$ \\
Median duration of wire marking (IQR), min & $30(27-44)$ \\
Wire marking-related complications, n (\%) & $1(5 \%)$ \\
Intraoperatively correct wire position, n (\%) & $18(90 \%)$ \\
LCRR & \\
Patients, $\mathrm{n}$ & 4 \\
Metastases, n & $6 / 56$ \\
\hline
\end{tabular}

WMM: Wire-marked metastases: LCRR: local complete radiological response. *Pneumothorax.

Van Vledder et al. turned their attention to the notion of resectability in 2008, stating that an increasing number of patients were being treated with systemic chemotherapy prior to liver resection, either administered as neoadjuvant treatment for initially resectable disease or in attempt to convert patients with unresectable disease into surgical candidates (17). At that time, the paradigm therefore was to aim for complete resection or ablation of all areas in the liver where disease was observed prior to chemotherapy, perhaps including resection of regions in which disease originally occurred but could not be found intraoperatively. However, limitations in visualizing or locating these disappearing
Table V. Follow-up data for latest follow-up at a median of 21.45 months.

\begin{tabular}{lc}
\hline Parameter & \\
\hline Median follow-up (IQR), months & $21.45(15.63-42.38)$ \\
Status at latest follow-up, $\mathrm{n}(\%)$ & $11(55 \%)$ \\
No evidence of disease & $7(35 \%)$ \\
Alive with disease & $2(10 \%)$ \\
Dead of disease & \\
\hline
\end{tabular}

CRLMs intraoperatively were seen as a potential danger in the sense of leaving these metastases untreated. In contrast to other research work, which was burdened with a lack of detailed resectability criteria (18), they defined these as the ability to completely resect all sites of metastasis while leaving a sufficient volume of hepatic remnant (>20-30\%), and adequate remnant vascular/biliary inflow and vascular outflow (19). Indeed, our method of CT-guided wire marking of metastatic tissue can improve resection to the smallest halo diameter, thereby securing eligibility and minimizing sacrifice of functional tissue. In our study, the survival rate was $55 \%$ after a median of 21.45 months of follow-up.

One of our tasks was also to make clear the difference between radiological and pathological responses to preoperative chemotherapy, which as stated before would justify a wire marking method for precise resection of metastatic tissue and avoidance of loss of healthy tissue. One of the first to describe this were Spolverato et al., who stated that progression during chemotherapy is a poor prognostic sign, and radiological and pathological responses are good prognostic indicators. They also noted that a subset of patients would be expected to have a complete radiographic response to with their CRLMs 'disappearing' on crosssectional imaging. The incidence of disappearing CRLMs in patients who receive preoperative chemotherapy for CRLM ranges from 7 to $24 \%$, depending on the quality and type of cross-sectional imaging. They also provided predictive parameters for the likelihood of a CRLM disappearing to be a true pathological response, such as carcinoembryonic antigen normalization, preoperative MRI usage in imaging of disappearing CRLMs and lower body mass index (BMI $\leq 30 \mathrm{~kg} / \mathrm{m}^{2}$ ) of the patient. These parameters were also used in our study protocol. In our study, $18(90 \%)$ of our patients showed a response to chemotherapy, but only $10(18 \%)$ resected metastatic sites had a histological response to chemotherapy, whilst 46 (82\%) metastatic sites had some form of metastatic tissue present. After noting the number of patients that had a mere radiological and those with full pathological response, a line between those two groups of patients can be drawn. Usually the patients with radiological 


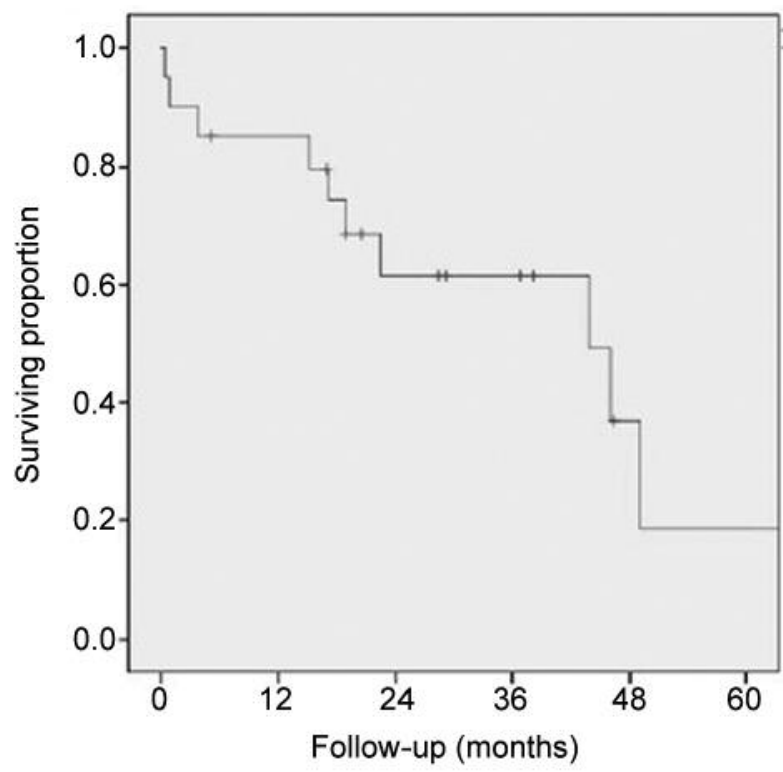

Figure 2. Kaplan-Meier plot of overall survival.

response only, disappearing CRLMs were left non-resected, which resulted in a high percentage of recurrence.

Benoist et al. noted back in 2006 that in their study overall, persistent macroscopic or microscopic residual disease or early recurrence in situ were observed in 55 out of $66(83 \%)$ having a complete response in imaging. For most of their patients receiving chemotherapy for CRLMs, a complete response by CT did not mean that they were cured.

In addition to previous studies described above, our research came to the conclusion that a more thorough method of distinguishing a true pathological and radiological response is needed. In our work, $82 \%$ of our patient samples of disappearing CRLMs still had metastatic tissue present (necrotic or vital), which was confirmed by histopathological analysis, and the method of CT-guided wire marking that we suggest was found to be useful in the more precise resection of disappearing CRLMs. The CTguided wire marking of CRLMs could change the view on the criteria for resectability of metastatic tissue towards greater inclusion, by contributing to more precise and costeffective resection, thereby securing greater survival rates. Instead of leaving disappearing CRLMs to theoretical discussion, we have come up with a cost-effective and simple-to-use method that allows surgeons to pinpoint metastatic sites precisely and extirpate them with maximal saving of healthy liver tissue.

Our follow-up results showed 11 (55\%) patients had no evidence of disease, which advocates for the wire-marking method as a successfully performed procedure.

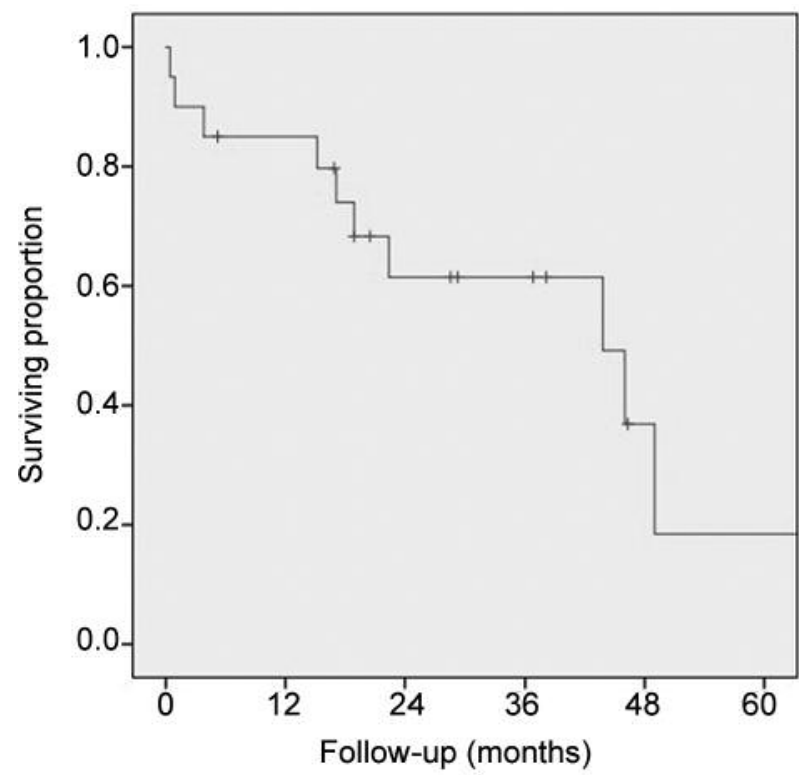

Figure 3. Kaplan-Meier plot of disease-free survival.

\section{Conflicts of Interest}

The Authors declare no conflicts of interest in regard to this study.

\section{Authors' Contributions}

K.P, M.H-J and S.H. J.V conceived and designed the study; K.P., M.H-J, B.H, performed the study; S.H. and K.P, B.H, M.H-J, M.K. recruited patients, collected and processed samples; and V.J. and W.V. contributed reagents/materials/analysis tools; and V.J, M.K. and K.P. wrote the article. All Authors declare they significantly participated in creation of the study. All Authors read and approved the final article.

\section{Acknowledgements}

The Authors would like to thank Fritz Seidl, M. A. Interpreting and Translating, for proof-reading and language-editing of this article.

\section{References}

1 Adams RB, Aloia TA, Loyer E, Pawlik TM, Taouli B and Vauthey JN: Selection for hepatic resection of colorectal liver metastases: Expert Consensus Statement. HPB 15(2): 91-103, 2013. PMID: 23297719. DOI: 10.1111/j.1477-2574.2012. 00557.x

2 Aloysius MM, Zaitoun AM, Beckingham IJ, Neal KR, Aithal GP, Bessell EM and Lobo DN: The pathological response to neoadjuvant chemotherapy with FOLFOX-4 for colorectal liver metastases: A comparative study. Virch Archiv 451(5): 943-948, 2007. PMID: 17805566. DOI: 10.1007/s00428-007-0497-1 
3 Aoki T, Murakami M, Koizumi T, Kusano T, Fujimori A, Enami Y, Matsuda K, Goto S, Watanabe M and Otsuka K: Preoperative tattooing for precise and expedient localization of landmark in laparoscopic liver resection. J Am Coll Surg 221(5): e97-e101, 2015. PMID: 26278038. DOI: 10.1016/j.jamcollsurg.2015. 07.444

4 Van Kessel CS, Samim M, Koopman M, van den Bosch MAAJ, Borel Rinkes IHM, Punt CJA and van Hillegersberg R: Radiological heterogeneity in response to chemotherapy is associated with poor survival in patients with colorectal liver metastases. Eur J Cancer 49(11): 2486-2493, 2013. PMID: 23692811. DOI: 10.1016/j.ejca.2013.03.027

5 Arnold D, Schmoll HJ, Lang H, Knoefel WT, Ridwelski K, Trarbach T, Staib L, Kirchner T, Geißler M, Seufferlein T, Amthauer H, Reiss H, Schlitt HJ and Piso P: Spezielle Therapiesituationen beim metastasierten kolorektalen Karzinom. Oncol Res Treat 33(Suppl 4): 8-18, 2010. PMID: 20431307. DOI: $10.1159 / 000308447$

6 Auer RC, White RR, Kemeny NE, Schwartz LH, Shia J, Blumgart LH, Dematteo RP, Fong Y, Jarnagin WR and D'Angelica MI: Predictors of a true complete response among disappearing liver metastases from colorectal cancer after chemotherapy. Cancer 116(6): 1502-1509, 2010. PMID: 20120032. DOI: $10.1002 /$ cncr.24912

7 Kornprat P, Schollnast H, Cerwenka H, Werkgartner G, Bernhardt $\mathrm{G}$ and Mischinger HJ: Management of colorectal liver metastases after complete response to neoadjuvant chemotherapy. A case of computer tomography-guided wire marking of the liver tumor. Int J Colorect Dis 24(1): 125-126, 2009. PMID: 18682963. DOI: 10.1007/s00384-008-0548-3

8 Passot G, Odisio BC, Zorzi D, Mahvash A, Gupta S, Wallace MJ, Kim BJ, Yamashita S, Conrad C, Aloia TA, Vauthey JN and Chun YS: Eradication of missing liver metastases after fiducial placement. J Gastrointest Surg 20(6): 1173-1178, 2016. PMID: 26791387. DOI: 10.1007/s11605-016-3079-1

9 Bischof DA, Clary BM, Maithel SK and Pawlik TM: Surgical management of disappearing colorectal liver metastases. Br J Surgery 100(11): 1414-1420, 2013. PMID: 24037559. DOI: 10.1002/bjs.9213

10 Elias D, Goere D, Boige V, Kohneh-Sharhi N, Malka D, Tomasic G, Dromain C and Ducreux M: Outcome of posthepatectomymissing colorectal liver metastases after complete response to chemotherapy: Impact of adjuvant intra-arterial hepatic oxaliplatin. Ann Surg Oncol 14(11): 3188-3194, 2007. PMID: 17705091. DOI: $10.1245 / \mathrm{s} 10434-007-9482-9$

11 Benoist S, Brouquet A, Penna C, Julie C, El Hajjam M, Chagnon S, Mitry E, Rougier P and Nordlinger B: Complete response of colorectal liver metastases after chemotherapy: Does it mean cure? J Clin Oncol 24(24): 3939-3945, 2006. PMID: 16921046. DOI: $10.1200 / \mathrm{JCO} .2006 .05 .8727$

12 Spolverato G, Vitale A, Ejaz A, Cosgrove D, Cowzer D, Cillo U and Pawlik TM: Hepatic resection for disappearing liver metastasis: A cost-utility analysis. J Gastrointest Surg 19(9): 1668-1675, 2015. PMID: 26077902. DOI: 10.1007/s11605-0152873-5

13 D'Angelica MI, Correa-Gallego C, Paty PB, Cercek A, Gewirtz AN, Chou JF, Capanu M, Kingham TP, Fong Y, DeMatteo RP, Allen PJ, Jarnagin WR and Kemeny N: Phase II trial of hepatic artery infusional and systemic chemotherapy for patients with unresectable hepatic metastases from colorectal cancer: conversion to resection and long-term outcomes. Ann Surg 261(2): 353-360, 2015. PMID: 24646562. DOI: 10.1097/ SLA.0000000000000614

14 Jang HJ, Kim BC, Kim HS, Kim JH, Song HH, Kim JB, Park JJ, Yoon SN, Woo JY and Zang DY: Comparison of RECIST 1.0 and RECIST 1.1 on computed tomography in patients with metastatic colorectal cancer. Oncology 86(2): 117-121, 2014. PMID: 24480800. DOI: 10.1159/000357714

15 Vigano L, Capussotti L, Lapointe R, Barroso E, Hubert C, Giuliante F, Ijzermans JN, Mirza DF, Elias D and Adam R: Early recurrence after liver resection for colorectal metastases: risk factors, prognosis, and treatment. A LiverMetSurvey-based study of 6,025 patients. Ann Surg Oncol 21(4): 1276-1286, 2014. PMID: 24346766. DOI: 10.1245/s10434-013-3421-8

16 Levi FA, Boige V, Hebbar M, Smith D, Lepere C, Focan C, Karaboué A, Guimbaud R, Carvalho C, Tumolo S, Innominato P, Ajavon Y, Truant S, Castaing D, De Baere T, Kunstlinger F, Bouchahda M, Afshar M, Rougier P, Adam R and Ducreux M: Conversion to resection of liver metastases from colorectal cancer with hepatic artery infusion of combined chemotherapy and systemic cetuximab in multicenter trial OPTILIV. Ann Oncol 27(2): 267-274, 2016. PMID: 26578731. DOI: 10.1093/ annonc/mdv548

17 Van Vledder MG, de Jong MC, Pawlik TM, Schulick RD, Diaz LA and Choti MA: Disappearing colorectal liver metastases after chemotherapy: Should we be concerned? J Gastrointest Surg 14(11): 1691-700, 2010. PMID: 20839072. DOI: 10.1007/ s11605-010-1348-y

18 Ferrero A, Langella S, Russolillo N, Vigano L, Lo Tesoriere R and Capussotti L: Intraoperative detection of disappearing colorectal liver metastases as a predictor of residual disease. J Gastrointest Surg 16(4): 806-814, 2012. PMID: 22258869. DOI: 10.1007/s11605-011-1810-5

19 Charnsangavej C, Clary B, Fong Y, Grothey A, Pawlik TM and Choti MA: Selection of patients for resection of hepatic colorectal metastases: Expert Consensus Statement. Ann Surg Oncol 13(10): 1261-1268, 2006. PMID: 16947009. DOI: 10.1245/s10434-006-9023-y

20 Chan G, Hassanain M, Chaudhury P, Vrochides D, Neville A, Cesari M, Kavan P, Marcus V and Metrakos P: Pathological response grade of colorectal liver metastases treated with neoadjuvant chemotherapy. HPB 12(4): 277-284, 2010. PMID: 20590898. DOI: 10.1111/j.1477-2574.2010.00170.x

21 Leichman L: Neoadjuvant chemotherapy for disseminated colorectal cancer: Changing the paradigm. J Clin Oncol 24(24): 3817-3818, 2006. PMID: 16921031. DOI: 10.1200/JCO. 2006.07.2546

22 Manfredi S, Lepage C, Hatem C, Coatmeur O, Faivre J and Bouvier AM: Epidemiology and management of liver metastases from colorectal cancer. Ann Surg 244(2): 254-259, 2006. PMID: 16858188. DOI: 10.1097/01.sla.0000217629.94941.cf

23 Ntourakis D, Memeo R, Soler L, Marescaux J, Mutter D and Pessaux P: Augmented reality guidance for the resection of missing colorectal liver metastases: An initial experience. World J Surg 40(2): 419-426, 2016. PMID: 26316112. DOI: 10.1007/ s00268-015-3229-8

24 Pessaux P, Chenard MP, Bachellier $P$ and Jaeck D: Consequences of chemotherapy on resection of colorectal liver metastases. J Visceral Surg 147(4): e193-201, 2010. PMID: 20655821. DOI: 10.1016/j.jviscsurg .2010.06.004 
25 Sturesson C, Nilsson J, Lindell G, Andersson RG and Keussen I: Disappearing liver metastases from colorectal cancer: impact of modern imaging modalities. HPB 17(11): 983-987, 2015. PMID: 26252426. DOI: $10.1111 / \mathrm{hpb} .12476$

26 Kemeny N: Presurgical chemotherapy in patients being considered for liver resection. Oncologist 12(7): 825-839, 2007. PMID: 17673614. DOI: 10.1634/theoncologist.12-7-825

27 Gruenberger B, Scheithauer W, Punzengruber R, Zielinski C, Tamandl D and Gruenberger T: Importance of response to neoadjuvant chemotherapy in potentially curable colorectal cancer liver metastases. BMC Cancer 8(1): 120, 2008. PMID: 18439246. DOI: $10.1186 / 1471-2407-8-120$
28 Dindo D, Demartines $\mathrm{N}$ and Clavien PA: Classification of surgical complications: a new proposal with evaluation in a cohort of 6336 patients and results of a survey. Ann Surg 240(2): 205-213, 2004. PMID: 15273542. DOI: 10.1097/01.sla.00001 33083.54934.ae

Received April 19, 2019

Revised May 30, 2019

Accepted June 4, 2019 